\title{
Assimilation of Mobile Marketing in Companies
}

\author{
Katarina Stanoevska-Slabeva \\ University of St. Gallen \\ katarina.stanoevska@unisg.ch \\ Thomas Wozniak \\ Lucerne University of Applied Sciences and Arts \\ thomas.wozniak@hslu.ch
}

\author{
Vera Lenz-Kesekamp \\ University of St. Gallen \\ vera.lenz-kesekamp@unisg.ch
}

Dorothea Schaffner

Lucerne University of Applied Sciences and Arts dorothea.schaffner@hslu.ch

\begin{abstract}
This paper explores the assimilation of mobile marketing (MM) in companies. By combining the technology-organization-environment framework and domestication theory, first a structural equation model is build and empirically tested with an online survey. The results show that mobile culture has a significant impact on MM goal achievement. A subsequent cluster analysis shows that there are three segments of companies applying MM: sophisticated, mediocre and unready MM adopters.
\end{abstract}

\section{Introduction}

In recent years, the adoption and usage of smartphones has dramatically increased. For users mobile devices are becoming the primary and most important access device for any type of available online information, services as well as transaction and interaction opportunities. This indisputable rise of mobile communication challenges companies and they have to adapt to the emerging mobile behavior of users. Therefore, mobile communication has a growing importance for companies [39] and mobile marketing (MM) has the potential to become the primary marketing channel [23].

The increasing importance of $\mathrm{MM}$ has given rise to research in this area. Several review articles [20], [28], [33], [4] show that most of prevailing research sheds light on customer adoption of MM. It provides insights for companies on how to successfully target users with MM. Main research topics include: acceptance of the different forms of MM by users, segmentations of MM users [2], [13]; analysis of experiences of users and their engagement with MM [9], [26]. Another research stream considers topics related to effectiveness and success factors of MM [8]. Subject of research have also been specific MM technologies, (e.g. SMS or Bluetooth [7], [16], [18]) and specific forms of MM (e.g. location- and permission-based marketing [18], [31]). Considerably less research addressed the adoption and assimilation of the various MM technologies from a company perspective [21], even though the introduction of $\mathrm{MM}$ poses various challenges to companies (see e.g. [5] or [25]). These challenges result from the diversity of $\mathrm{MM}$ instruments (e.g. mobile websites, native and hybrid apps, in-app advertising, QR-codes and others) and the specific characteristics of mobile technology. Examples of questions that companies face are: the choice of the appropriate mix of MM technologies; the integration of $\mathrm{MM}$ within the overall digital marketing strategy and with other digital communication channels; the integration of $\mathrm{MM}$ instruments with other technology as customer relationship management; or the division of responsibilities among the marketing and other departments and teams within the company. To take on these challenges, organizations have developed different assimilation approaches for MM, but there is little research related to the question on which specific solutions were selected by companies, and whether MM is effectively integrated into companies. The paper at hand contributes to fill this gap by analyzing the assimilation of MM on the example of Swiss companies. The main research question is: How do companies implement and assimilate MM?

To answer this question, a multi-method research approach was applied involving literature review, analysis of factors influencing the assimilation of MM by companies, and cluster analysis of companies using MM. The literature review was the basis for the definition and conceptualization of MM. By adjusting and combining the technology-organization-environment (TOE) framework with domestication theory (DT), a structural-equation research model was created. The model was applied for analyzing factors influencing the use of MM in companies. It revealed that cultural aspects have a significant impact on the ability of companies to achieve marketing goals with 
MM. This motivated a subsequent deeper analysis of the similarities and differences of MM assimilation in companies by way of cluster analysis of companies using MM. Three different segments of companies applying MM were discovered: sophisticated, mediocre and unready MM adopters.

The remainder of this paper is structured as follows: Chapter 2 describes the development of the structural equation model and the results of its empirical testing. Chapter 3 is dedicated to the cluster analysis and describes the segments of companies using MM. Chapter 4 provides a discussion of the results, reflects upon limitations of the study, and provides an outlook on further research.

\section{Factors Influencing the Assimilation of Mobile Marketing in Organizations}

\subsection{Theoretical Background and Model}

MM was conceptualized and its components were identified based on literature review. By combining the definition of [24] and [33], MM is defined as a set of practices that enable organizations to communicate and engage with their audience in an interactive and relevant manner by using a mobile medium, device or technology. Examples of MM technology and instruments are mobile websites, native or hybrid apps, mobile advertising, messaging services, or location based marketing (LBM) - to name a few. As current statistics show [11], the attractiveness of the mobile channel has motivated many companies to introduce MM into their digital marketing portfolio. The research focus of the paper at hand is on the question how the different MM assimilation and implementation approaches of companies are influencing both the MM instruments used and MM goal achievement. The goal is to gain insights into how companies can better master the process of $\mathrm{MM}$ assimilation by understanding the determinants of effective MM implementation on company level. Thus, the focus of the investigation are not companies that are in the process of initial adoption of MM, but companies that already apply MM.

In literature, there are only few theoretical models that are addressing adoption and implementation of information technology (IT) on organizational level [1], [27]. According to [27], these are diffusion of innovation theory (DOI) and TOE. Thereby, compared to DOI, TOE is considered as broader and more widely empirically tested [27]. Given this and by following the approach of [29], TOE was selected as one basic theory for constructing the research model used for the analysis of the factors influencing the use of MM. However, in its original form, TOE was developed for the analysis of factors influencing the initial technology adoption decision by companies and does not consider factors affecting assimilation of technology after it. Another theory that considers assimilation of technology after initial adoption is the domestication theory (DT) [34]. Thus, the model for evaluating the factors affecting effective assimilation of MM was constructed based on the combination of TOE (see e.g. [1]) and DT (see e.g. [14]). According to the review of [28], this is a suitable approach as TOE has to be adjusted to fit the specific characteristics of different technologies and was already combined with other theories in several published studies dedicated to analysis of technology assimilation (see e.g. [29]).

Tornatzky and Fleischer [37] proposed the technology-organization-environment framework (TOE). It is an organizational-level theory according to which three different elements of a company's context influence adoption of innovations and technology (see also [1], [37]): the environmental, technological, and organizational context. As suggested by [36], these elements are "both constraints and opportunities for technological innovation". The goal of the study at hand is the analysis of the use of MM by companies that have already adopted and assimilated MM. As suggested by Harwood [14], the acquisition of technology is considered merely being the starting point in the useful life of the technology. Thus, the three contexts were operationalized and adjusted to fit this research goal and the specific MM setting (see also [21]).

The environmental context refers to the structure of the industry in which the investigated company is active [1]. The focus of the study at hand is rather on the question wether the specific target market (i.e. B2C or B2B market) of a company influences the way how MM is used and assimilated [40]. Thus, the antecedent variable "environmental context" was adjusted to reflect the target market of MM.

The technology context of TOE refers to the attitude of companies towards the technology they intend to adopt. The goal of the analysis in this paper is to explore factors that influence the assimilation of MM in companies. Thus, in accordance with [30], the original TOE was adjusted so that the dependent variable is not adoption of MM technology, but the actual use of MM technologies and the capability of companies to achieve marketing goals with it.

Based on published summaries of various applications of TOE ([27] and [29]), the organizational context refers to descriptive measures about the organization such as scope, size and managerial structure. However, as [35] mentioned, the adoption and assimilation of new technologies is 
influenced not only by company external factors but also by company internal factors. Internal factors influencing technology adoption might be culture [19], management approach [32], overall attitude towards technological innovation [32] and others. Thus, in order to get deeper insights on how MM is integrated in companies, the scope of the organizational context has been extended to include also internal organizational factors that have been defined by referring to domestication theory.

The domestication theory (DT) has its origins in media and technology studies [14]. It describes the process by which innovations, in particular new technology, are 'tamed' or appropriated by its users. The theory was initially developed to help understand the adoption and use of new media technologies by households [34], but has since been expanded in the innovation literature as a tool to understand technologies and innovations entering any consuming unit [14], [30] (i.e. workplace, country, or others) that can be analyzed economically, culturally and sociologically. Silverstone et al. [34] formulated the domestication framework "to understand the internalization of information and communication technologies" and defined it as "a process in which a technology becomes embedded within a local context of use". Lie and Sørensen [22] added with applying a more technological lens that domestication "is a way of describing social learning about technologies". Domestication of technology is a process consisting of four phases [14]: appropriation, objectification, incorporation, and conversion. In the process of domestication, the new technology is transferred from the outside to the inside of a company ("appropriated"), embedded in the company ("objectified"), integrated in the daily routines ("incorporated") and finally transformed into a symbol of the company ("converted") [34]. In this way, the new technologies are captured and integrated into the organizational culture [14]. Thus, domestication highlights the negotiations, challenges to power and control, rule-making and breaking that accompany the introduction of technologies into any social setting [14], [19]. In sum, by combining elements from TOE and the DT, the research model shown in Figure 1 was constructed.

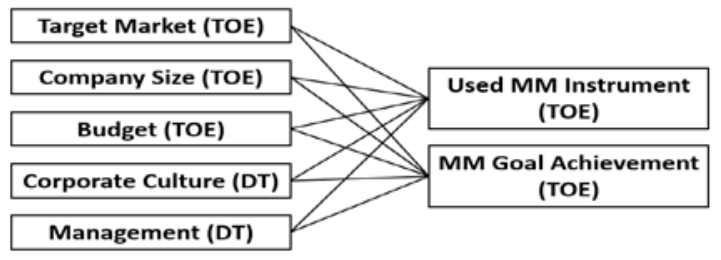

Figure 1: Research model
In order to conform with the specific goal of this study, TOE was adjusted in the following way: 1 ) the external context is set to reflect the different target markets of MM; 2) the technology context is set to reflect the use of available MM technologies; 3) the dependent variable "technology adoption" was transformed to reflect technology use and capability to achieve MM goals; and 4) the organizational context was extended with elements from DT related to culture and management.

Based on the research model, the following ten hypotheses were defined:

H1: Target Market of MM (B2B or B2C) has no impact on the used MM instruments.

H2: Target Market of MM (B2B or B2C) has no impact on MM goal achievement.

H3 to H6: Higher \{company size, budget, stronger mobile culture, or higher management involvement with $M M$ \} will lead to a higher number of used $M M$ instruments.

H7 to H10: Higher \{company size, budget, stronger mobile culture, and higher management involvement with $M M$ \} will lead to greater levels of $\mathrm{MM}$ goal achievement.

\subsection{Research methodology and measures}

The research model was operationalized with an online questionnaire. The items of the questionnaire were based on a five-point Likert scale as well as dichotomous and multiple-choice questions. They were generated by referring to the above mentioned theories and literature as summarized in Table 1.

The survey was sent to one representative of companies that worked in the broad field of MM and had staff responsibility. First, the authors tried to approach companies directly. As this did not result in sufficient answers, additional companies were selected in cooperation with the biggest Swiss telecom provider that also provides MM consultancy and applications to Swiss companies. Based on this cooperation, it was possible to select out of the customer database of the Swiss telecom provider only companies that already apply MM and to approach persons responsible for MM in that companies. All contacted companies were either Swiss companies, or had a major branch located in Switzerland and were active on the Swiss market. Despite of the fact that all companies were active at the Swiss market, the resulting sample cannot be considered as representative for Switzerland. Out of total 1200 contacted companies, 129 completed the online survey. The participating companies were of different size: 17 companies had $\leq 49$; $30 \leq 249$; 50 between 250-2'499; and 32 companies $\geq 2$ '500 employees. 58 
Table 1. Origin and operationalization of the research model

\begin{tabular}{|c|c|c|}
\hline Variable & Items & Explanation \\
\hline $\begin{array}{l}\text { Target Market } \\
\text { (TOE) }\end{array}$ & B2C; B2B \& B2C; B2B & $\begin{array}{l}\text { Additive index according to the TOE adjustment } \\
\text { discussed in section } 2.1 \text { (see also [29]) }\end{array}$ \\
\hline $\begin{array}{l}\text { Company Size } \\
\text { (TOE) }\end{array}$ & $\leq 49 ; \leq 249 ; 250-2,499 ; \geq 2,500$ employees & $\begin{array}{l}\text { According to the classification of the Swiss } \\
\text { Federal Statistical Office }\end{array}$ \\
\hline $\begin{array}{l}\text { Budget (TOE) } \\
\% \text { of digital } \\
\text { marketing budget } \\
\text { for MM }\end{array}$ & Open & $\begin{array}{l}\text { Clustering of the open answers to }<10 \% \text { (low), } \\
<35 \% \text { (moderate), and }<80 \% \text { (high) portion of } \\
\text { overall digital marketing budget for } \mathrm{MM}\end{array}$ \\
\hline $\begin{array}{l}\text { Corporate Culture } \\
\text { (DT) } \\
\text { Mobile Culture }\end{array}$ & $\begin{array}{l}\text { 1) high risk tolerance related to mobile, } \\
\text { 2) strongly internalized mobile thinking, 3) high } \\
\text { willingness to change internal processes to fit a } \\
\text { mobile way of working, 4) strong focus on creating } \\
\text { mobile experience for the customers, 5) seeing } \\
\text { failures in relation to mobile as a chance to improve, } \\
\text { 6) proactive working atmosphere between various } \\
\text { departments in relation to mobile, 7) integration of } \\
\text { various marketing channels (incl. MM) in the } \\
\text { corporate culture, 8) management support for MM } \\
\text { and mobile sales, and 9) leading role in the digital } \\
\text { transformation process }\end{array}$ & $\begin{array}{l}\text { According to the review article [19], the } \\
\text { predominant theoretical approach to culture has } \\
\text { been to conceptualize it in terms of values } \\
\text { defining either national, organizational, or IT } \\
\text { culture. Furthermore, [17] and [6] concluded in } \\
\text { their research that successful technology } \\
\text { assimilation requires either the technology to fit } \\
\text { the organizational culture or the culture to be } \\
\text { shaped to fit the behavioral requirements of the } \\
\text { technology. Organizational stakeholders attribute } \\
\text { certain values to IT that are denoted by [19] as IT } \\
\text { values. Based on these findings from literature, } \\
\text { the variable "culture" was operationalized as } \\
\text { "mobile culture" by identification of specific } \\
\text { mobile IT values and necessary organizational fit } \\
\text { for mobile technology (see for example [32]). }\end{array}$ \\
\hline $\begin{array}{l}\text { Management } \\
\text { (DT) }\end{array}$ & $\begin{array}{l}\text { 1) dedicated mobile strategy or roadmap, 2) } \\
\text { independent single initiatives in relation to mobile, 3) } \\
\text { central guidelines for new MM initiatives, 4) project- } \\
\text { based MM initiatives, 5) overarching strategy for } \\
\text { MM initiatives and 6) cross-department discussion } \\
\text { and coordination of MM initiatives }\end{array}$ & Following [3] with special attention to MM \\
\hline $\begin{array}{l}\text { Used MM } \\
\text { Instruments } \\
\text { (TOE) }\end{array}$ & $\begin{array}{l}\text { 1) responsive and mobile websites, 2) native or } \\
\text { hybrid apps, 3) responsive web apps, 4) native or } \\
\text { hybrid tablet-only apps, 5) mobile advertising, 6) in } \\
\text { app advertising in own or 7) in apps owned by other } \\
\text { companies, 8) SMS and 9) MMS advertising, 10) } \\
\text { messaging services, 11) QR-codes, 12) mobile } \\
\text { coupons as well as 13) indoor and 14) outdoor } \\
\text { location based marketing }\end{array}$ & $\begin{array}{l}\text { Extracted from literature based on literature } \\
\text { review (see for example [4], [7], [8], [9], [18], } \\
\text { [20], [26], [28]) }\end{array}$ \\
\hline $\begin{array}{l}\text { MM goal } \\
\text { achievement } \\
\text { (TOE) }\end{array}$ & $\begin{array}{l}\text { 1) brand awareness, 2) providing information about } \\
\text { products, 3) interaction with the customers, 4) } \\
\text { generation of leads, 5) conversion and transactions, 6) } \\
\text { customer loyalty, 7) word of mouth (WOM) and 8) } \\
\text { establishing an image as an innovative company }\end{array}$ & $\begin{array}{l}\text { Additive index comprised of eight indicators } \\
\text { related to typical marketing goals (see e.g. [10]) }\end{array}$ \\
\hline
\end{tabular}

companies were active on the $\mathrm{B} 2 \mathrm{C}$ market, 39 on the $\mathrm{B} 2 \mathrm{~B}$ and B2C, and 32 on the B2B market.

For testing the hypothesized causal relationships among the research model variables, structural equation modeling was applied by using Mplus. Including the standardized coefficients, the results referred to the Maximum-Likelihood-estimation (MLM) and the total variance explained (R-squared) for all the dependent constructs without missing values $(\mathrm{N}=57)$. The model fit was assessed with established fit indices based on the Chi-squared test and a combination of four additional fit indices recommended by [15]: the comparative fit index (CFI), the Tucker-Lewis index (TLI), the root mean square error of approximation (RMSEA), and the standardized root mean square of residuals (SRMR).

After the removal of two items of the management variable, which showed AVE values slightly below the required threshold, all scales showed good results and are considered as reliable 
and were thus used in the analyses. The model itself provided mixed fit indices. The Chi-squared test demonstrated a good fit. However, CFI, TLI, SRMR and RMSEA are below the typically required threshold. One reason for this could be that the sample was rather small $(\mathrm{N}=57)$ after excluding missing data, whereas the model was complex with 20 paths. Therefore, the results should be interpreted with care. $\mathrm{Hu}$ and Bentler [15], who cautioned that when the sample size is small, the RMSEA tends to over reject true population models, support this assumption. Thus, overall the model is rather interesting due to the good results for the Chi-squared test and for the confirmatory factor analysis.

The results of the structural equation modeling revealed that seven of the twenty hypothesized and estimated paths are significant $(\mathrm{p} \leq 0.05)$. The first dependent variable used $M M$ instruments is impacted by company size and budget. The larger the company (250-2'499 employees) the higher the probability that more MM instruments are used $(\beta=0.334)$. The number of used $M M$ instruments is furthermore, influenced by moderate budget $(\leq 35 \%)(\beta=0.240)$. A significant direct influence from target market, mobile culture, and management on used MM instruments could not be confirmed.

MM goal achievement was mainly influenced by strong mobile culture $(\beta=0.559)$ followed by mid mobile culture $(\beta=0.407)$. It was furthermore significantly affected by mid budget $(\leq 35 \%)$ with reference to low budget $(\beta=0.234)$. The applied management has also an impact on MM goal achievement $(\beta=0.253)$. The remaining variables target market, company size and high budget $(\leq 80 \%)$ don't have significant direct impact on MM goal achievement. In general, it can be stated that the stronger the mobile culture is, the higher the influence on MM goal achievement.

\section{Cluster Analysis}

In order to better understand the impact of mobile culture and to get more detailed insights about the differences of companies with respect to it, additional exploratory research was conducted with cluster analysis. A hierarchical cluster analysis was implemented using the Ward's method (see e.g. [12] and [39]) based on the nine variables that measure how mobile culture varies in the companies. Of a two-, three-, four-, five- and six-cluster solution, the three cluster solution was considered as the best option to clearly distinguish the different clusters of mobile culture.

The quality of the clustering solution was tested with a discriminant analysis, which confirmed the suitability of the selected variables. The results showed (see Table 2) that the three clusters significantly varied from one another and provided a good model fit. In sum, $95.9 \%$ of the originally grouped cases were correctly classified.

Table 2.

Wilks' Lambda for discriminant functions

\begin{tabular}{lcccc}
\hline \hline $\begin{array}{l}\text { Test of } \\
\text { Functions }\end{array}$ & $\begin{array}{c}\text { Wilks' } \\
\text { Lambda }\end{array}$ & $\begin{array}{c}\text { Chi- } \\
\text { square }\end{array}$ & df & Sig. \\
\hline \hline 1 through 2 & .177 & 116.193 & 18 & .000 \\
\hline 2 & .746 & 19.673 & 8 & .012 \\
\hline \hline
\end{tabular}

The highest discriminatory power appeared in the variables "high willingness to change internal processes to fit a mobile way of working", "strong focus on creating mobile experience for the customers", "strongly internalized mobile thinking", and "integration of various marketing channels (incl. MM) in the corporate culture". The lowest discriminatory power was clearly evident in the variable "high risk tolerance related to mobile". Finally, the means of these factors were compared based on Kruskal Wallis Test statistics, as shown in Table 3.

\subsection{The three MM segments}

Based on the hierarchical cluster analysis, we identified three different segments of companies applying MM: sophisticated MM adopters with strong mobile culture, mediocre MM adopters with some mobile values, and unready MM adopters, which use MM sporadically without a specific mobile culture (see also Table 3). In the following, the means of assessed characteristics have been compared and ANOVA has been conducted to assess differences among the three segments. Means and standard deviations for all factors were computed as well. The three segments can be described in detail as follows:

Sophisticated MM Adopters: Out of our sample, $13.5 \%$, i.e. 10 companies were identified to belong to the segment of sophisticated MM adopters: 3 of them belong to the financial sector (banks and insurance), 3 to the retail sector, 2 to transport and logistics, and 2 to the tourism sector. Companies belonging to this segment are characterized with strong mobile culture, i.e. appear to have strong consensus on mobile IT values in the company. They are rather medium size companies and employ 250 - 499 employees. Sophisticated MM adopters invest around $40 \%$ of the overall digital budget for mobile activities. Main reasons of these companies to implement $\mathrm{MM}$ are: to fulfill their customers' requirements $(M=4.60$, $\mathrm{p}<0.001$ ); to fulfill their performance promise 
Table 3. Means, SDs and Kruskal Wallis test of mobile culture indicators

\begin{tabular}{lcccc}
\hline \hline Corporate Culture Indicators & $\begin{array}{c}\text { Sophisticated } \\
\text { MM Adopters }\end{array}$ & $\begin{array}{c}\text { Mediocre } \\
\text { MM } \\
\text { Adopters }\end{array}$ & $\begin{array}{c}\text { Unready } \\
\text { MM } \\
\text { Adopters }\end{array}$ & $\begin{array}{c}\text { Kruskal } \\
\text { Wallis Test } \\
\text { (Asymp. Sig) }\end{array}$ \\
\hline High Risk Tolerance Related to Mobile & 3.50 & 2.74 & 2.64 & 0.075 \\
& $(.850)$ & $(1.077)$ & $(1.025)$ & \\
\hline Strongly Internalized Mobile Thinking & 4.40 & 2.72 & 2.00 & 0.000 \\
& $(.516)$ & $(.818)$ & $(1.034)$ & 0.000 \\
\hline High Willingness to Change Internal Processes & 4.70 & 3.08 & 1.55 & \\
to Fit a Mobile Way of Working & $(.483)$ & $(.895)$ & $(1.163)$ & 0.000 \\
\hline Strong Focus on Creating Mobile Experience & 4.50 & 3.47 & 1.55 & \\
for the Customers & $(.707)$ & $(.992)$ & $(1.218)$ & 0.002 \\
\hline Seeing Failures in Relation to Mobile as a & 3.90 & 3.26 & 2.36 & 0.000 \\
Chance to Improve & $(.876)$ & $(0.923)$ & $(.983)$ & 0.000 \\
\hline Proactive Working Atmosphere between & 3.70 & 3.08 & 1.45 & \\
Various Departments in Relation to Mobile & $(.823)$ & $(.829)$ & $(1.030)$ & 0.000 \\
\hline Integration of Various Marketing Channels & 4.30 & 3.11 & 1.82 & $(1.044)$ \\
(incl. MM) in the Corporate Culture & $(.483)$ & $(.847)$ & 2.45 & \\
\hline Management Support for MM and Sales & 4.50 & 3.79 & $(1.122)$ & \\
& $(.850)$ & $(.988)$ & 1.73 & 0.000 \\
\hline Leading Role in the Digital Transformation & 4.40 & 2.57 & $(1.193)$ & \\
Process & $(.516)$ & $(1.047)$ & & \\
\hline \hline
\end{tabular}

( $\mathrm{M}=4.33, \mathrm{p}<0.05)$, to develop new customer segments $(M=4.20, \mathrm{p}<0.001)$, and to get access to new customers $(M=4.20, p<0.001)$. About $50 \%$, of the sophisticated MM adopters consider themselves capable to individualize their MM communications and to differentiate between customer segments. $60 \%$ of the companies were also able to differentiate dynamically between users.

Mediocre MM Adopters: This is the largest segment and includes $71.6 \%$ of the companies in the sample $(N=53)$. Most of the companies of this segment also stem from the financial industry (30.2\%) as well as transport and logistics (18.9\%). The estimated budget for $\mathrm{MM}$ in this cluster amounted to $50 \%$ of the overall digital marketing budget. These companies employed between 500 and 2'499 employees. The companies use MM for the following reasons: fulfilling the customers' needs $(\mathrm{M}=4.54, \mathrm{p}<$ $0.001)$, developing additional access to customers $(\mathrm{M}=$ 4.02, $\mathrm{p}<0.05$ ), extending existing products and services $(\mathrm{M}=3.92)$, and accessing new customer segments $(M=3.81, p<0.001) .37 .3 \%$ of the mediocre $\mathrm{MM}$ adopters are able to differentiate between customer segments. Only $29.4 \%$ of the mediocre $\mathrm{MM}$ adopters are able to differentiate dynamically among users. However, those who were capable to individualize their MM campaigns were similar to sophisticated MM adopters.

Unready MM Adopters: $14.9 \%$ of the companies in the sample were characterized as unready MM adopters $(N=11)$. Four of the companies in this segment stem from the industrial sector followed by three companies in the financial sector. The majority of the companies had between 500 and 2'499 employees. This segment invests the lowest budget for MM activities (10\%). Unready MM adopters indicated that they implement MM because they want to fulfill the customers' needs $(\mathrm{M}=3.55, \mathrm{p}<0.001)$, to extend existing products and services $(\mathrm{M}=3.55)$, and to develop new products and services $(M=3.30)$. Out of our sample, four of the unready MM adopters were able to individualize their MM communications. Only one company was capable to differentiate dynamically between users.

\subsection{Comparison of the MM Segments}

In the following, all segments are described in more detail with reference to the variables applied in the structural equation model: market orientation, used MM instruments and MM goal achievement. The analysis showed no significant differences between the three clusters regarding the factor target market (e.g. B-C or B-B).

Cross tabulations with Chi-square tests were employed to profile the clusters with regard to the 14 item of the variable used mobile instruments. The results revealed that the surveyed companies mostly differ regarding in-app advertising in apps from other companies $(\mathrm{p}<0.10)$ and messaging services ( $p$ $<0.10$ ), as shown in Table 4. Sophisticated MM 
adopters obtained higher scores in nearly all used $M M$ instruments, excluding native or hybrid apps, responsive web app, native or hybrid tablet-only apps, and mobile coupons. They seem to adopt emerging mobile innovations as in-app advertising in apps owned by others as well as messaging services (e.g. WhatsApp) faster than the companies from the two other segments, in particular the unready MM adopters. Compared to the two other segments, unready

Table 4. Percentage of used mobile instruments

\begin{tabular}{lccc}
\hline $\begin{array}{l}\text { MM } \\
\text { Instruments }\end{array}$ & $\begin{array}{c}\text { Sophistic } \\
\text { ated MM } \\
\text { Adopters }\end{array}$ & $\begin{array}{c}\text { Mediocre } \\
\text { MM } \\
\text { Adopters }\end{array}$ & $\begin{array}{c}\text { Unready } \\
\text { MM } \\
\text { Adopters }\end{array}$ \\
\hline \hline $\begin{array}{l}\text { Responsive } \\
\text { Website }\end{array}$ & $80.0 \%$ & $67.9 \%$ & $63.6 \%$ \\
\hline $\begin{array}{l}\text { Mobile } \\
\text { Website }\end{array}$ & $50.0 \%$ & $45.3 \%$ & $36.4 \%$ \\
\hline $\begin{array}{l}\text { Native or } \\
\text { hybrid App }\end{array}$ & $70.0 \%$ & $73.6 \%$ & $72.7 \%$ \\
\hline $\begin{array}{l}\text { Responsive } \\
\text { Web App }\end{array}$ & $20.0 \%$ & $24.5 \%$ & $36.4 \%$ \\
\hline $\begin{array}{l}\text { Native or } \\
\text { hybrid Tablet- } \\
\text { only App }\end{array}$ & $30.0 \%$ & $35.8 \%$ & $18.2 \%$ \\
\hline $\begin{array}{l}\text { Mobile } \\
\text { Advertising }\end{array}$ & $70.0 \%$ & $60.4 \%$ & $63.6 \%$ \\
\hline $\begin{array}{l}\text { In-App } \\
\text { Advertising in } \\
\text { own App }\end{array}$ & $30.0 \%$ & $24.5 \%$ & $9.1 \%$ \\
\hline $\begin{array}{l}\text { In-App } \\
\text { Advertising in } \\
\text { other Apps }\end{array}$ & $\mathbf{4 0 . 0 \%}$ & $\mathbf{2 4 . 5 \%}$ & $\mathbf{0 . 0 \%}$ \\
\hline $\begin{array}{l}\text { SMS / MMS } \\
\text { Messaging }\end{array}$ & $50.0 \%$ & $34.0 \%$ & $27.3 \%$ \\
\hline $\begin{array}{l}\text { Services } \\
\text { Qndool LBM }\end{array}$ & $\mathbf{6 0 . 0 \%}$ & $\mathbf{5 2 . 8 \%}$ & $\mathbf{1 8 . 2 \%}$ \\
\hline $\begin{array}{l}\text { Outdoor LBM } \\
\text { Mobile }\end{array}$ & $30.0 \%$ & $22.6 \%$ & $63 \%$ \\
\hline
\end{tabular}

MM adopters implement far less MM marketing instruments. This indicates a sporadic and isolated use of $\mathrm{MM}$ in these companies.

Table 5 presents means and one-way ANOVA results on the capability to achieve MM marketing goals in the companies of the three segments. The ANOVA analysis showed significant statistical differences with reference to all MM goal achievement items. Sophisticated MM adopters are able to better achieve MM marketing goals than mediocre and unready MM adopters are. They are in particular capable of positioning themselves as innovative companies based on intensive use of MM. This item showed the highest statistically significant differences between the three segments (see Table 5).

Table 5. Means of MM goal achievement

\begin{tabular}{|c|c|c|c|}
\hline $\begin{array}{l}\text { Marketing } \\
\text { Goals }\end{array}$ & $\begin{array}{l}\text { Sophistic } \\
\text { ated MM } \\
\text { Adopters }\end{array}$ & $\begin{array}{l}\text { Mediocre } \\
\text { MM } \\
\text { Adopters }\end{array}$ & $\begin{array}{l}\text { Unready } \\
\text { MM } \\
\text { Adopters }\end{array}$ \\
\hline $\begin{array}{l}\text { Brand } \\
\text { Awareness }\end{array}$ & $4.44 \dagger$ & $4.11 \dagger$ & $3.45 \dagger$ \\
\hline $\begin{array}{l}\text { Provide } \\
\text { Product } \\
\text { Information }\end{array}$ & $4.50 *$ & $4.17 *$ & $3.55^{*}$ \\
\hline $\begin{array}{l}\text { Interactions } \\
\text { with the } \\
\text { Customers }\end{array}$ & $4.60 *$ & $3.96 *$ & $3.27 *$ \\
\hline Leads & $4.00 \dagger$ & $3.84 \dagger$ & $3.00 \dagger$ \\
\hline $\begin{array}{l}\text { Conversion } \\
\text { and } \\
\text { Transactions }\end{array}$ & $4.00 *$ & $3.96 *$ & $2.91 *$ \\
\hline $\begin{array}{l}\text { Customer } \\
\text { Loyalty }\end{array}$ & $4.00 *$ & $3.74 *$ & $2.50 *$ \\
\hline $\begin{array}{l}\text { Word of } \\
\text { Mouth }\end{array}$ & $3.78 *$ & $3.58 *$ & $2.40 *$ \\
\hline $\begin{array}{l}\text { Image as } \\
\text { Innovative } \\
\text { Company }\end{array}$ & $4.30 * * *$ & $3.79 * * *$ & $2.36 * * *$ \\
\hline
\end{tabular}

As shown in Table 6, the one-way ANOVA results revealed with regards to management, significant differences for dedicated mobile strategy or roadmap ( $\mathrm{p}<0.001)$ and overarching strategy for MM initiatives ( $p<0.01$ ) between the three clusters. Sophisticated MM adopters obtained furthermore higher scores in all management factors than mediocre and unready MM adopters. This indicates that sophisticated MM adopters are characterized with strong management support for mobile MM initiatives and a well-orchestrated MM strategy over the various applied MM instruments.

Overall comparison of the MM segments: The in-depth analysis of the three clusters reveals three different approaches to MM assimilation. A favorable environment for effective assimilation of MM was created by sophisticated MM adopters. The main characteristics of such a favorable environment are: a 
Table 6. Management

\begin{tabular}{lccc}
\hline \hline Management & $\begin{array}{c}\text { Sophisticat } \\
\text { ed MM } \\
\text { Adopter }\end{array}$ & $\begin{array}{c}\text { Mediocre } \\
\text { MM } \\
\text { Adopters }\end{array}$ & $\begin{array}{c}\text { Unready } \\
\text { MM } \\
\text { Adopters }\end{array}$ \\
\hline \hline $\begin{array}{l}\text { Dedicated } \\
\text { Mobile } \\
\text { Strategy or } \\
\text { Roadmap }\end{array}$ & $3.56^{* * *}$ & $2.83^{* * *}$ & $1.36^{* * *}$ \\
\hline $\begin{array}{l}\text { Central } \\
\text { Guidelines for } \\
\text { new MM }\end{array}$ & 2.80 & 2.67 & 2.45 \\
Initiatives & & & \\
\hline $\begin{array}{l}\text { Overarching } \\
\text { strategy for }\end{array}$ & $4.00^{* *}$ & $3.10^{* *}$ & $1.90^{* *}$ \\
$\begin{array}{l}\text { MM } \\
\text { Initiatives }\end{array}$ & & & \\
\hline \hline
\end{tabular}

Note: $\uparrow \mathrm{p}<0.10,{ }^{*} \mathrm{p}<0.05,{ }^{* *} \mathrm{p}<0.01,{ }^{* * *} \mathrm{p}<0.001$

strong mobile culture reflecting high overall affinity of the company to mobile innovations, management support for MM and a common strategy for the various MM initiatives. All this favors and results in an effective implementation of MM with high potential to reach MM goals. With this attitude towards mobile innovation, companies of this segment are capable to position themselves as innovators and forerunners in the market. They are able to achieve these results with in average lower portion of the budget for digital marketing for $\mathrm{MM}$ compared to companies belonging to the segment of mediocre MM adopters. While mediocre MM adopters invest in average $50 \%$ of the overall digital marketing budget for MM, sophisticated MM adopters achieve better results with in average $40 \%$ of the digital marketing budget for MM. Compared to sophisticated MM adopters, mediocre MM adopters have a less pronounced mobile culture in particular with respect to risk tolerance related to mobile and the level of internalized mobile thinking (see Table 3). All this results in a lower ability to reach MM goals. The fact that sophisticated MM adopters are rather mid-size companies while the segment of mediocre $\mathrm{MM}$ adopters comprises rather larger companies (500 - 2'499 employees) indicates that midsize companies might be more flexible and can easier adopt culturally to mobile innovation.

The results of the segment analysis indicate furthermore that unready MM adopters use MM sporadically and concentrate on simple isolated MM solutions. The considerable lower values for all variables for companies from this segment clearly shows that adoption of technology that is subsequently not sufficiently embedded in the company has less potential to result in positive effects.

\section{Discussion and Conclusion}

In order to get insights on how companies assimilate MM, a multi-method research approach was applied. First, in order to get an aggregated view on factors influencing the assimilation of $\mathrm{MM}$ in companies, a structural equation model was created by combining TOE and DT. The model was operationalized and an online survey was conducted among 129 Swiss companies from various industries and size. The structural equation analysis revealed that mobile culture is the major factor impacting MM goal achievement. To get a more in-depth view on assimilation of $\mathrm{MM}$, an additional cluster analysis was conducted. The cluster analysis resulted in three clusters: sophisticated, mediocre and unready MM adopters. The multi-method research provided the following major results: Company size and budget matter and have an impact on the combination of MM instruments used by companies. The bigger the size of a company and higher the budget the more MM instruments are used. This finding implies on the one hand that, due to the complexity of $\mathrm{MM}$, there are constraints for smaller companies to use $\mathrm{MM}$ in a more comprehensive manner. On the other hand, MM goal achievement is rather impacted by mobile culture and management. This confirms existing findings in literature related to the importance of culture [19] in the context of technology adoption by companies. The segment analysis showed that sophisticated MM adopters mainly represented by mid-size companies, are able to better achieve MM goals with relatively less budget and mobile instruments used. Both results taken together imply that not only the size and height of the budget matters, but also how MM is used and assimilated.

The major scientific contributions of the paper can be summarized as follows: The analysis showed clearly that efficient assimilation of $\mathrm{MM}$ in organization requires an appropriate corporate environment in which the technology is "domesticated", i.e. "objectified" and "incorporated". It also illustrates that not only the initial decision of a company to adopt a technology matters, but also how it is subsequently assimilated in the company. In times of intensive digital transformation of all industries, this also shows the need for further research related to domestication and assimilation of IT. Another scientific contribution is the combination and extension of the TOE with internal company context such as culture and management from the DT towards a model for evaluation of assimilation of 
technology in companies. Another contribution is the MM specific operationalization of the resulting model suitable for assessment of MM. Finally, the combination of the two research methods (structural equation and cluster analysis) proved as valuable to get the big and detailed picture about the assimilation of MM in Swiss companies. Overall, the paper introduces a new methodology and model, and points out to consider adoption of technology as a complex assimilation process.

The practical contribution of the paper is the finding about the importance of mobile specific culture and the need for creation of a favorable environment in companies to achieve effective assimilation of MM and technology in general.

One major limitation of the study is that some of the statistical tests for the model failed, even though the values were close to the required ones. This might be explained with the small size of the sample, which is a further limitation of the study. As the study was conducted with a sample of Swiss companies, it only provides an indication of MM assimilation in Switzerland. Other countries might provide different results. Thus, in future research the model has to be verified with a bigger sample and in other countries.

Acknowledgement: This research has been funded by the Swiss Commission for Technology and Innovation (CTI) (Project no 17663.1 PFES-ES), and it was realized with the support of several industry partners (Aperto Schweiz AG, Post CH AG, Swisscom (Schweiz) AG, Magazine zum Globus AG, Raiffeisen Schweiz Genossenschaft).

\section{References}

[1] Baker, J. 2012. "The technology-organizationenvironment framework," in Information systems theory, Dwivedi, Y.K. et al. (ebs.), Springer New York, pp. 231-245.

[2] Banerjee, S., and Roy Dholakia, R. 2013. "Situated or ubiquitous? A segmentation of mobile e-shoppers," International Journal of Mobile Communications (11:5), pp. 530-557.

[3] Berghaus, S., and Back, A. 2016. "Wie packen Unternehmen die digitale Transformation an? Ratgeber und Fallstudien zur Strategiearbeit für das digitale Zeitalter,“ Studien-Publikation, T-Systems Multimedia Solutions GmbH (ebs.).

[4] Billore, A., and Sadh, A. 2015." Mobile advertising: A review of the literature," The Marketing Review (15:2), pp. 161-183.

[5] Brady, M., Fellenz, M.R, and Brookes, R. (2008), "Researching the role of information and communications technology (ICT) in contemporary marketing practices", Journal of Business \& Industrial Marketing, Vol. 23 Iss 2 pp. 108 - 114

[6] Cabrera, A., Cabrera, E.F., and Baraja, S. 1999. "Organizational Culture as a Determinant of Technology Assimilation,” Business Economics Series (12), pp. 1-24.

[7] Chang, Y. 2013. “Age matters: Short Message Service advertising reading behaviours,” International Journal of Mobile Communications (11:2), pp. 159175.

[8] Chiem, R., Arriola, J., Browers, D., Gross, J., Limman, E., Nguyen, P.V., Sembodo, D., Song, Y., and Seal, K.C. 2010. "The Critical Success Factors for Marketing with Downloadable Applications: Lessons Learned from Selected European Countries,” International Journal of Mobile Marketing (5:2), pp. 43-56.

[9] Dickinger, A., and Kleijnen, M. 2008. "Coupons Going Wireless: Determinants of Consumer Intentions to Redeem Mobile Coupons," Journal of Interactive Marketing (22:3), pp. 23-39.

[10] Eisinger, T., Rabe, L., and Thomas, W. (ebs) 2009. Performance Marketing - Erfolgsbasiertes Online-Marketing: Mehr Umsatz im Internet mit Suchmaschinen, Bannern, E-Mails \& Co. BusinessVillage (3).

[11] eMarketer: Mobile to Account for More than Half of Digital Ad Spending in 2015. (2015) available online: http://bit.ly/1JItdqW .

[12] Everitt, B.S., Landau, S., Leese, M., and Stahl, D. 2011. Cluster Analysis, 5th Edition, John Wiley \& Sons, Ltd., Chichester.

[13] Goneos-Malka, A., Strasheim, A., and Grobler, A.F. 2014. "Conventionalists, Connectors, Technoisseurs and Mobilarti: Differential profiles of mobile marketing segments based on phone features and postmodern characteristics of consumers,” Journal of Retailing and Consumer Services (21), pp. 905-916.

[14] Harwood, S. A. 2011. “The domestication of online technologies by smaller businesses and the 'busy day'," Information and Organization (21), pp. 84-106.

[15] Hu, L.-T., and Bentler, P. M. 1999. "Cutoff criteria for fit indexes in covariance structure analysis: Conventional criteria versus new alternateves,” Structural Equation Modeling (6:1), pp. 1-55.

[16] Idwan, S., Alramouni, S., Al-Adhaileh, M., and Al-Khasawneh, A. 2008. "Enhancing mobile advertising via Bluetooth technology,” Information and Organization (6:5), pp. 587-597. 
[17] Kaarst-Brown, M.-L., and Robey, D. 1999. "More on myth, magic and metaphor. Cultural insights into the management of information technology in organizations," Information Technology \& People (12:2), pp. 192 - 218.

[18] Kang, J.-Y., Munb, J.M, and Johnson, K. 2015. "In-store mobile usage: Downloading and usage intention toward mobile location-based retail apps," Computers in Human Behavior (46), pp. 210-217.

[19] Leidner, D.E., and Kayworth, T. 2006. “A Review of Culture in Information Systems Research: Toward a Theory of Information Technology Culture Conflict,“ MIS Quarterly (30:2), pp. 357-399.

[20] Leppäniemi, M., Sinisalo, J., and Karjaluoto, H. 2006. “A Review of Mobile Marketing Research,“ International Journal of Mobile Marketing (1:1), pp. 30-40.

[21] Leppäniemi, M., and Karjaluoto, H. 2008. "Mobile Marketing: From Marketing Strategy to Mobile Marketing Campaign Implementation,“ International Journal of Mobile Marketing (3:1), pp. 50-61

[22] Lie, M., \& Sørensen, K.H. (1996). Making technologies our own? Domesticating technology into everyday life. In Merete Lie \& Knut H. Sørensen (Eds.), Making technologies our own? Domesticating technology into everyday life (pp. 1-30). Oslo: Scandinavian University Press

[23] McRae, E., Carrabis, J., Carrabis, S., and Hamel, S. 2013. "Want to be Loved? Go Mobile!," International Journal of Mobile Marketing (8:2), pp. 55-66.

[24] Mobile Marketing Association 2009. "MMA Updates Definition of Mobile Marketing," available online: $\quad$ www.mmaglobal.com/news/mma-updatesdefinition-mobile-marketing (retrieved 05-04-2016).

[25] Mort, G.S. and Drennan, J. 2002. "Mobile Digital Technology: emerging issues for marketing. Journal of Database Marketing, Vol. 10 (1), pp. 9-23.

[26] Muk, A., and Babin, B.J. 2006. “Consumers’ intentions to opt in to SMS advertising - A cross-national study of young Americans and Koreans," International Journal of Mobile Marketing (1:1), pp. 21-29

[27] Oliveira, T., and Martins, M. F. 2011. "Literature Review of Information Technology Ad-option Models at Firm Level" The Electronic Journal Information Systems Evaluation (14:1), pp. 110- 121.

[28] Park, T., Shenoy, R., and Salvendy, G. 2008. "Effective advertising on mobile phones: a literature review and presentation of results from 53 case studies,” Behaviour \& Information Technology (27:5), pp. 355-373.

[29] Picoto, W.N., Bélanger, F. and Palma-dos-Reis, A. (2014). “A technology-organisation-environment
(TOE)-based m-business value instrument', Int. J. Mobile Communications, Vol. 12, No. 1, pp.78-101.

[30] Pierson, J. 2005. "Domestication at work in small businesses," in Domestication of media and technology, Berker, T., Hartmann, M., Punie, Y., and Ward, K. (Eds.). Berkshire: Open University Press, pp. 205-226.

[31] Richard, J.E., and Meuli, P.G. 2013. "Exploring and modelling digital natives' intention to use permission-based location-aware mobile advertising," Journal of Marketing Management (29:5-6), pp. 698719.

[32] Sammer, Th. 2013. "Why is there variation in the nature of organizational mobile adoption? an empirical study of the influence of organizational culture on organizational mobile IT adoption”. Proceedings of the $12^{\text {th }}$ International Conference on mobile business, Berlin, Germany, June 2013.

[33] Shankar, V., and Balasubramanian, S. 2009. "Mobile Marketing: A Synthesis and Prognosis," Journal of Interactive Marketing (23:2), pp. 118-129.

[34] Silverstone, R., Hirsch, E., and Morley, D. 1992. "Information and communication technologies and the moral economy of the household," Consuming technologies: Media and information in domestic spaces, R. Silverstone, and E. Hirsch (Eds.), London: Routledge, pp. 15-31.

[35] Stoica, M., Miller, D. W., and Stotlar, D. 2005. "New technology adoption, business strategy and government involvement: the case of mobile commerce," Journal of Nonprofit and Public Sector Marketing, 13 (1/2), pp. 213-232.

[36] Tornatzky, L. G., and Fleischer, M. 1990. The processes of technological innovation, Lexington, MA: Lexington Books.

[37] Wang, Y.-S., Li, H.-T., Li, C.-R., and Zhang, D.Z. 2016. "Factors affecting hotels' adoption of mobile reservation systems: A technology-organizationenvironment framework," Tourism Management (53), pp. 163-172.

[38] Wedel, M., and Kamakura, W.A. 2000. Market Segmentation: Conceptual and Methodological Foundations. 2nd Edition, Boston, MA Springer US.

[39] Vatanparast, R., and Butt, A.H. 2010. “An Empirical Study of Factors Affecting Use of Mobile Advertising," International Journal of Mobile Marketing (5:1), pp. 28-40.

[40] Zhu, K., Kraemer, K., and Xu, S. 2003. "Electronic business adoption by european firms: A cross-country assessment of the facilitators and inhibitors,” European Journal of Information Systems (12:4), pp. 251-268. 